\title{
BCcivis
}

\section{MECHANICAL BEHAVIOUR OF POLYPROPYLENE AND STEEL FIBER SELF-CONSOLIDATING CONCRETE}

\author{
Vitor Moreira de Alencar Monteiro ${ }^{(1)}$ and Flávio de Andrade Silva ${ }^{(1)}$ \\ (1) Department of Civil and Environmental Engineering, Pontifícia Universidade Católica do \\ Rio de Janeiro, Brazil
}

https://doi.org/10.21452/bccm4.2018.02.06

\begin{abstract}
This article presents the results of an experimental investigation on the mechanical behavior of a self-consolidating concrete reinforced with steel and polypropylene fibers. Hooked end steel fibers were used as reinforcement in fiber volume fractions of $0.25 \%, 0.50 \%$ and $1.00 \%$. Polypropylene fibers were used as reinforcement in volume fractions of $0.33 \%, 0.66 \%$ and $1.10 \%$.

Pre-notched concrete prims were tested under three point bending tests. The tests were controlled by the crack mouth opening displacement in order to have a better analysis of the post cracking regime. Although the use of steel fibers promoted higher values of flexural residual stress due to its geometrical and material properties, the addition of polypropylene fibers promoted higher residual resistance for higher values of CMOD.

The mechanical behavior of the addition of the fibers were explained by pullout tests. This significant difference is associated not only with the fiber type, but also with the fiber anchorage. While the polypropylene fiber in concrete matrix is associated only with the interfacial shear stress, the hooked end steel fiber presents another component associated with the anchorage of the hook, promoting higher values of pullout resistance.
\end{abstract}

\section{INTRODUCTION}

The addition of fibers to enhance the mechanical behavior of concrete has been widely used for many years, but its practical use in structural engineering applications still rely on the development of technical standards to guarantee its safety. While the use of fibers considerably improves mechanical properties such as ductility and crack-width control [1], it does not change the compressive strength and the modulus of elasticity [2] of the composite.

This improvement is associated with the difficulty of crack opening and propagation. The fibers act as a bridge mechanism across the crack surfaces, promoting a strain-hardening or a softening behavior after the appearance of the first crack. This effect is dependent on the fibermatrix interface, fiber tensile strength and fiber geometry [1]. The bridging mechanism presents not only an improvement in toughness, but also promotes a long-term residual resistance [3].

FRC has been widely used in many engineering applications such as stabilization of rock excavations. Fiber reinforced shotcrete, in combination with other support elements, can 
provide effective ground support after blasting or excavation with the development of flexural strength and toughness [4]. The advantage of fiber reinforced shotcrete over shotcrete with wire mesh is associated with labor and time saving, material reduction and improved safety.

Steel fibers is the more conventional reinforcement used due to its high elasticity modulus, which promotes strength in high volume fractions and post-peak load carrying capacity [5]. The synthetic fibers also showed important improvements associated with strain capacity and crack control of fiber reinforced concrete despite its low elasticity modulus [6]. Hence, the use of polypropylene fibers can be an alternative to steel fibers when the post cracking residual strength is not the main objective of the objective of the fiber reinforcement.

Pajak and Ponikiewski [7] conducted a study on the flexural behavior of self-compacting concrete reinforced with straight and hooked end steel fibers. The post-peak behavior of the composite was analyzed through three point bending tests in accordance with RILEM TC 152TDF [8] and EN14651 [9]. While the deflection-hardening response was observed the selfcompacting concrete was reinforced with the hooked end fibers, the addition of straight fibers reported a softening response after reaching its peak. The increase of fiber volume ratio was responsible for increasing the flexural tensile strength with a higher increase of fracture energy for the hooked end steel fiber.

On the other hand, the addition of synthetic fiber in concrete reported distinct results when compared with steel fibers. Cifuentes et al. [6] showed that the presence o synthetic fiber in the concrete mix increased the mechanical properties and ductility. In lower strength concrete, the effect of the fiber is more remarkable due to lower stresses in the cohesive zone. Therefore, the bridge effect with presence of the fibers showed a greater influence.

The effect of steel and polypropylene fibers on the mechanical properties of the selfconsolidating FRC are addressed in this work. Three fiber volume fractions were tested for each fiber type. All the compositions were analyzed by bending tests based on the European standard EN 14651 [9]. Finally, pullout tests were carried on both polypropylene and hooked end steel fibers with the aim to better understand the bond mechanism in the concrete matrix.

\section{GENERAL SPECIFICATIONS}

\subsection{Materials}

The cementitious materials used in the production of the self-compacting concrete were the Brazilian cement type CPV, fly ash and silica fume. Two classes of particle size of river sand were used: one ranging from $0.15 \mathrm{~mm}$ to $4.8 \mathrm{~mm}(\mathrm{~S} 1)$ and the other ranging from $0.15 \mathrm{~mm}$ to $0.85 \mathrm{~mm}$ (S2). Coarse aggregate with maximum diameter of $9.5 \mathrm{~mm}$, silica flour (ground quartz) and superplasticizer (Glenium 51 ) were also mixed together with the other materials. The average compressive strength after 28 days was $73 \mathrm{MPa}$ and the obtained slump spreading was $750 \mathrm{~mm}$ for a water/cement ratio of 0.5 . For more information on the mix procedure and matrix mechanical behavior refer to Pereira [10] and Rambo [11].

\section{2 $\quad$ Fiber Types}

One steel fiber with hooked end (SF) and one polypropylene fiber (PPF) were used as reinforcement. The steel fiber (SF) presented a length of $30 \mathrm{~mm}$ with an aspect ratio of 45 (d = $0.62 \mathrm{~mm}$ ) while the PPF presented a length of $40 \mathrm{~mm}$ and aspect ratio of $74(\mathrm{~d}=0.54)$. Other properties of the used fibers, according to their manufacturers, are presented in Table 1.

Table 1: Fiber Properties.

Properties
SF
PP 
View

Fiber Type

Fiber Shape

Length (mm)

Diameter (mm)

Aspect Ratio

Tensile Strength (MPa)

Elastic Modulus (Gpa)

Density $\left(\mathrm{g} / \mathrm{cm}^{3}\right)$

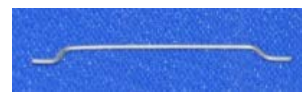

Dramix 3D 45/30

Hooked end

30

0.62

45

$1270+/-7.5 \%$

210

7.85

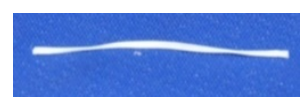

TUF Strand SF

Monofilament

40

0.54

74

600-650

9.5

\subsection{Mixing Procedure}

To evaluate the effects of the fibers on the mechanical properties of the composite, seven different mixtures were produced. The first one associated with the matrix without fibers and three mixtures with steel fiber volume fractions of $0.25 \%\left(20 \mathrm{~kg} / \mathrm{m}^{3}\right), 0.50 \%\left(40 \mathrm{~kg} / \mathrm{m}^{3}\right)$ and $1.00 \%\left(80 \mathrm{~kg} / \mathrm{m}^{3}\right)$ named, respectively, as C0.25\%SF, C0.50\%SF and C1.00\%SF. Moreover, other three mixtures were tested with polypropylene fiber volume fractions of $0.33 \%\left(3 \mathrm{~kg} / \mathrm{m}^{3}\right)$, $0.66 \%\left(6 \mathrm{~kg} / \mathrm{m}^{3}\right)$ and $1.10 \%\left(10 \mathrm{~kg} / \mathrm{m}^{3}\right)$ named as C0.33\%PPF, C0.66\%PPF and $\mathrm{C} 1.10 \% \mathrm{PPF}$. The amount of water, sand, cement and the other supplies for the seven mixtures is presented at Tables 2 and 3. For pullout tests, the matrix composition was produced without the total amount of coarse aggregate.

The mixing procedure was conducted through five main stages. First, all the aggregates (sands S1, S2 and coarse aggregate) were mixed together with $70 \%$ of the water for 1 minute with the help of a concrete mixer (previously wet). All additives (silica fume, fly ash and silica flour) were also added to the mix and blended for 1 minute. Afterwards the total amount of cement was added and mixed for another minute. All the superplasticizer was added to the mix with the remaining water and then blended with the rest of the materials for 10 minutes. Finally, the total amount of fibers was mixed for another 5 minutes. The specimens were cured for 28 days at room temperature of $24.4^{\circ} \mathrm{C}$ and $65.7 \%$ of humidity before testing.

Table 2: Mix composition of the matrix and steel fiber reinforced concrete.

\begin{tabular}{ccccc}
\hline & \multicolumn{4}{c}{ Mixtures } \\
\cline { 2 - 5 } Constituent & Matrix & $\mathrm{C} 0.25 \%$ SF & $\mathrm{C} 0.5 \% \mathrm{SF}$ & $\mathrm{C} 1.00 \% \mathrm{SF}$ \\
& & & & \\
& & & & \\
Coarse aggregate $(\mathrm{G})\left(\mathrm{kg} / \mathrm{m}^{3}\right)$ & 492.04 & 485.29 & 478.54 & 465.04 \\
Sand (S1) $\left(\mathrm{kg} / \mathrm{m}^{3}\right)$ & 826.71 & 826.71 & 826.71 & 826.71 \\
Sand (S2) $\left(\mathrm{kg} / \mathrm{m}^{3}\right)$ & 99.60 & 99.60 & 99.60 & 99.60
\end{tabular}




\begin{tabular}{ccccc} 
Silica Mesh $325(\mathrm{SM})\left(\mathrm{kg} / \mathrm{m}^{3}\right)$ & 70 & 70 & 70 & 70 \\
Cement $(\mathrm{C})\left(\mathrm{kg} / \mathrm{m}^{3}\right)$ & 360 & 360 & 360 & 360 \\
Fly Ash (FA) $\left(\mathrm{kg} / \mathrm{m}^{3}\right)$ & 168 & 168 & 168 & 168 \\
Silica Fume $(\mathrm{SF})\left(\mathrm{kg} / \mathrm{m}^{3}\right)$ & 45 & 45 & 45 & 45 \\
Superplasticizer $(\mathrm{SP})(\%)$ & $6.0 \%$ & $6.0 \%$ & $6.0 \%$ & $6.0 \%$ \\
Water $(\mathrm{W})\left(\mathrm{kg} / \mathrm{m}^{3}\right)$ & 155.65 & 155.65 & 155.65 & 155.65 \\
SF $\left(\mathrm{kg} / \mathrm{m}^{3}\right)$ & 0 & 20 & 40 & 80 \\
PPF $\left(\mathrm{kg} / \mathrm{m}^{3}\right)$ & 0 & 0 & 0 & 0 \\
Water/Cement ratio & 0.50 & 0.50 & 0.50 & 0.50 \\
\hline
\end{tabular}

* Sand (S2): Sand (S1) with diameter less than $0.85 \mathrm{~mm}$.

Table 3: Mix composition of polypropylene fiber reinforced concrete.

\begin{tabular}{cccc}
\hline & \multicolumn{3}{c}{ Mixtures } \\
\cline { 2 - 4 } Constituent & C0.33\%PPF & C0.66\%PPF & C1.10\%PPF \\
& & & \\
\hline Coarse aggregate $(\mathrm{G})\left(\mathrm{kg} / \mathrm{m}^{3}\right)$ & 483.24 & 474.43 & 462.69 \\
Sand (S1) $\left(\mathrm{kg} / \mathrm{m}^{3}\right)$ & 826.71 & 826.71 & 826.71 \\
Sand (S2) $\left(\mathrm{kg} / \mathrm{m}^{3}\right)$ & 99.60 & 99.60 & 99.60 \\
Silica Mesh 325 $(\mathrm{SM})\left(\mathrm{kg} / \mathrm{m}^{3}\right)$ & 70 & 70 & 70 \\
Cement $(\mathrm{C})\left(\mathrm{kg} / \mathrm{m}^{3}\right)$ & 360 & 360 & 360 \\
Fly Ash (FA) $\left(\mathrm{kg} / \mathrm{m}^{3}\right)$ & 168 & 168 & 168 \\
Silica Fume $(\mathrm{SF})\left(\mathrm{kg} / \mathrm{m}^{3}\right)$ & 45 & 45 & 45 \\
Superplasticizer $(\mathrm{SP})(\%)$ & $6.0 \%$ & $6.0 \%$ & $6.0 \%$ \\
Water $(\mathrm{W})\left(\mathrm{kg} / \mathrm{m}^{3}\right)$ & 155.65 & 155.65 & 155.65 \\
SF $\left(\mathrm{kg} / \mathrm{m}^{3}\right)$ & 0 & 0 & 0 \\
PPF $\left(\mathrm{kg} / \mathrm{m}^{3}\right)$ & 3 & 6 & 10 \\
Water/Cement ratio & 0.50 & 0.50 & 0.50 \\
\hline
\end{tabular}

* Sand (S2): Sand (S1) with diameter less than $0.85 \mathrm{~mm}$.

\section{TEST PROGRAM}

\subsection{Three Point Bending Test}

For the three point bending test, three specimens with $150 \mathrm{~mm}$ x $150 \mathrm{~mm} \times 550 \mathrm{~mm}$ were produced for each concrete mix in accordance with EN14651 [9]. The span between supports was $500 \mathrm{~mm}$ and the bottom side of each sample was notched with a $25 \mathrm{~mm}$ depth using a 3 $\mathrm{mm}$ diamond saw. These measurements and details are presented in Figures 1(a) and 1(b).

The tests were carried on using a MTS servo-controlled hydraulic testing machine with a closed loop type of control and a load cell of $100 \mathrm{kN}$. The tests were conducted at a constant rate of $0.10 \mathrm{~mm} / \mathrm{min}$ and controlled by the CMOD (Crack Mouth Opening Displacement) using a clip-gauge and limited to $4 \mathrm{~mm}$ opening. 


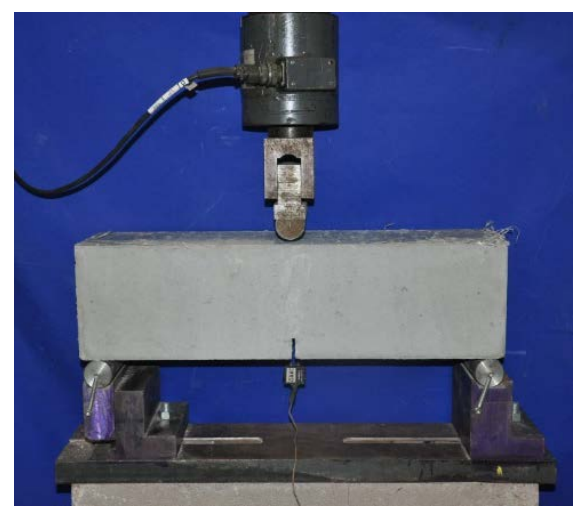

(a)

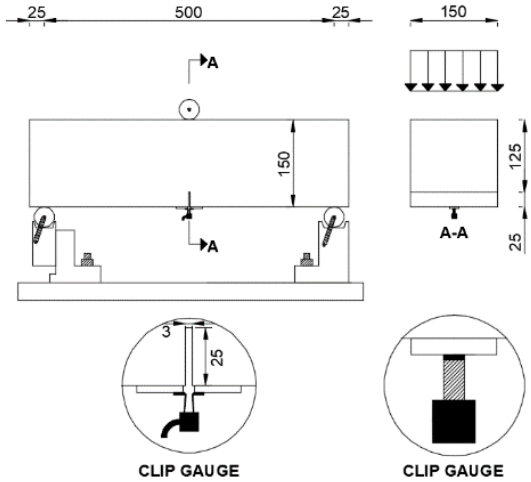

(b)

Figure 1. (a) Three point bending test setup. (b) Setup details in accordance with EN14651 [9]. All dimensions in mm.

\subsection{Pullout Tests}

The pullout tests were performed using a MTS 810 servo-controlled hydraulic-system, with $250 \mathrm{kN}$ capacity. With a $2.5 \mathrm{kN}$ cell attached to the crosshead, the tests were controlled by the internal LVDT displacement at a rate of $1.5 \mathrm{~mm} / \mathrm{min}$. The tests were limited to a maximum displacement of $25 \mathrm{~mm}$. Ten cylindrical specimens measuring $20 \mathrm{~mm}$ of diameter and $25 \mathrm{~mm}$ of embedment (Lf) were prepared for each tests series. The polypropylene fiber was pulled out with a rigid plate fixed with two bolts and the hooked-end steel fiber was clamped with a metal claw. The specimens were fixed at the bottom inside a metal cup. The complete test setup for both fibers is presented in Figures 2(a) and 2(b). For more information about the pullout tests refer to Castoldi [12].

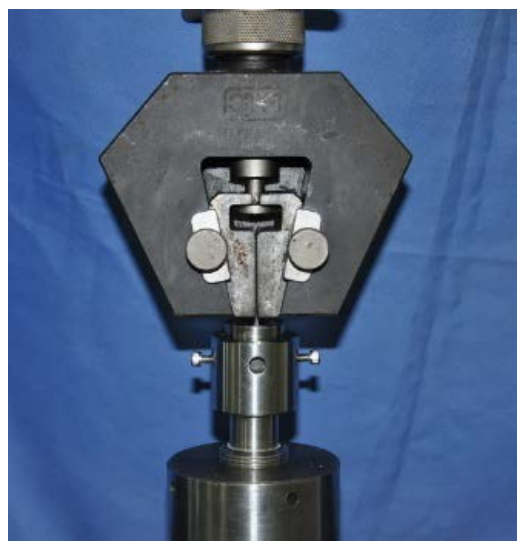

(a)

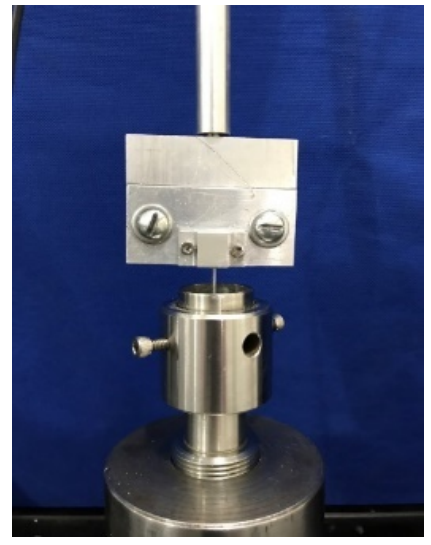

(b)

Figure 3. Pullout test setup for (a) steel and (b) polypropylene fibers.

\section{DISCUSSION AND ANALYSIS}

The presented stress-CMOD curves at Figures 4(a), 4(b) and 4(c) report the flexural response obtained on plain prisms, specimens reinforced with $0.25 \%, 0.50 \%$ and $1.00 \%$ of volume fractions of hooked end steel fibers and prisms reinforced with $0.33 \%, 0.66 \%$ and $1.10 \%$ of polypropylene fiber. Each stress-CMOD curve is associated with the average result of three tested specimens. The mechanical behavior of plain self-compacting concrete (specified 
as 'Matrix' in Fig. 4) is associated with a brittle material with linear elastic zone before cracking followed by a fast stress decrease with the increase in CMOD.

The use of hooked end steel fibers significantly enhanced the mechanical behavior of the composite, especially the residual stress and tenacity. The use of $0.25 \%$ and $0.50 \%$ of SF presented a similar behavior with a strain-softening response after reaching its peak. However, the addition of $1.00 \%$ of steel fiber in concrete was responsible for a strain-hardening behavior before reaching the ultimate stress capacity.

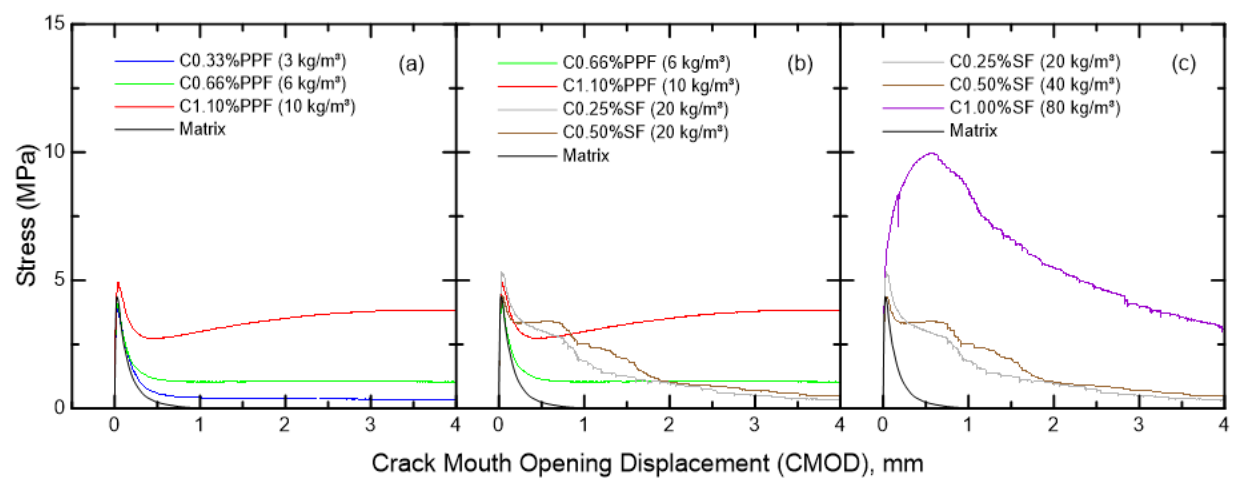

Figure 4. Results from three point bending tests: (a) SCC with different volume ratios of polypropylene fibers. (b) Comparison between polypropylene and steel fiber SCC. (c) SCC with different volume ratios of hooked end steel fibers.

As expected, the post-peak stage of the stress-CMOD curve differs much when comparing steel with polypropylene fibers. Although the addition of synthetic fibers indicated a sudden drop after the peak load, the residual strength remained almost constant after reaching CMOD levels of $0.5 \mathrm{~mm}$. The $1.10 \%$ polypropylene fiber reinforcement indicated a slight increase in resistance when reaching higher CMOD levels.

It possible to see through Figure 4(b) that the use of high volume fractions of polypropylene can result in higher residual flexural stress when compared with the addition of steel fibers. Especially for CMOD values greater than $2 \mathrm{~mm}$, the use of $0.66 \%$ and $1.10 \%$ PPF in concrete reports higher values of flexural resistance.

The mechanical behavior polypropylene and steel fiber reinforced concretes can be explained by the bond between of the fiber in the concrete matrix. Figure 5(a) presents the mean curve of the pullout tests for both SF and PPF. In the case of the PPF, the pullout load does not present a sudden drop of resistance after reaching the peak load, it exhibits an unstable growth until reaching its maximum value at $14 \mathrm{~mm}$ of slip. The almost constant pullout strength with increasing slip promotes the post-peak behavior of the PPF reinforced concrete.

The significant difference in the residual resistance is associated with the fiber anchorage. The anchorage effect provided by the hook plays the leading role in increasing the pullout load [1], improving the the post-peak resistance of the composite. Figure 5(b) illustrates the difference in the interfacial shear mechanism between the PPF and SF. 


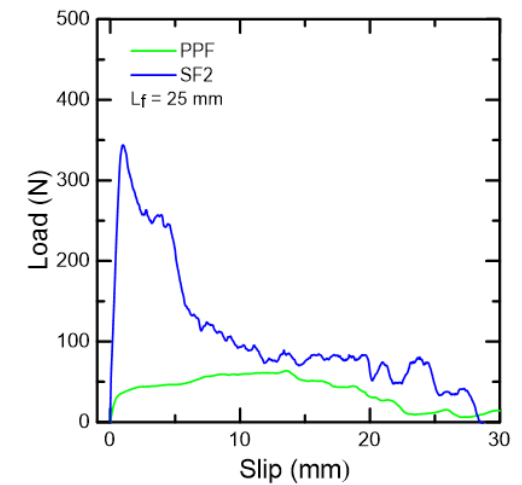

(a)

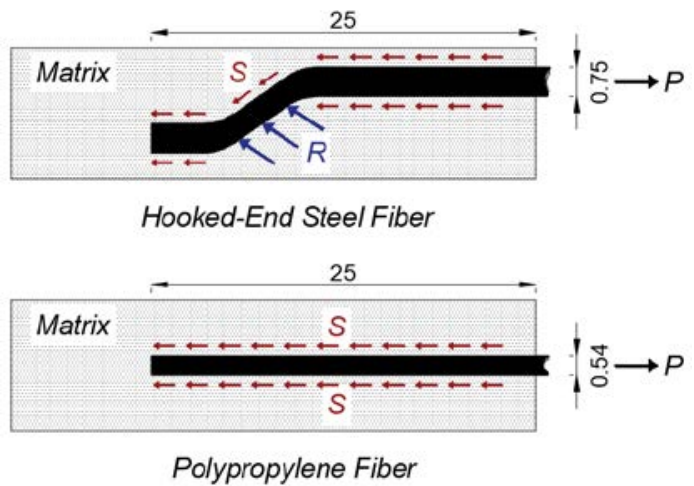

(b)

Figure 5. (a) Pullout results. (b) Bond of hooked-end steel and polypropylene fibers in the concrete matrix, where $\mathrm{S}$ is the interfacial shear stress, $\mathrm{R}$ is the normal component due to the mechanical anchorage of the hook and $\mathrm{P}$ is the pullout load. All dimensions in $\mathrm{mm}$.

\section{CONCLUSIONS}

The following general conclusions can be drawn from the present work:

- The use of lower volume fractions $(0.25 \%$ and $0.50 \%)$ of steel fibers in concrete promotes similar flexural resistance after peak when compared with the addition of $0.66 \%$ and $1.10 \%$ of polypropylene fiber. While the use of steel fibers presents a rapid decrease of strength after peak, the PPF reinforced concrete reported constant residual strength with increasing CMOD. Hence, the use of PPF in concrete promoted higher residual strength for higher values of CMOD.

- The main difference between polypropylene and hooked end steel fibers reinforcements can be explained through the bond of the fibers in concrete. The PPF presented almost constant strength with increasing slip, while the pullout tests with SF presented a gradual decrease in load after reaching peak. The higher pullout strength of the hooked end steel fiber is also associated with the presence of the hook, which promotes a stronger bond due to its mechanical anchorage.

\section{REFERENCES}

[1] A. Bentur, S. Mindess, "Fiber reinforced cementitious composites”. Second Ed: Taylor \& Francis, London, 2007.

[2] A. Alsalman, C. N. Dang, G. S. Prinz, and W. M. Hale, "Evaluation of modulus of elasticity of ultra-high performance concrete,” Constr. Build. Mater., vol. 153, pp. 918-928, 2017.

[3] A. E. Naaman, "High Performance Fiber Reinforced Cement Composites," High Perform. Constr. Mater. Sci. Appl., no. 5, pp. 91-153, 2008.

[4] J. M. Yang, J. K. Kim, and D. Y. Yoo, "Performance of shotcrete containing amorphous fibers for tunnel applications,” Tunn. Undergr. Sp. Technol., vol. 64, pp. 85-94, 2017.

[5] A. E. Naaman and H. W. Reinhardt, "Proposed classification of HPFRC composites based on their tensile response,” Mater. Struct. Constr., vol. 39, no. 289, pp. 547-555, 2006. 
[6] H. Cifuentes, F. García, O. Maeso, and F. Medina, "Influence of the properties of polypropylene fibres on the fracture behaviour of low-, normal- and high-strength FRC," Constr. Build. Mater., vol. 45, pp. 130-137, 2013.

[7] M. Pająk and T. Ponikiewski, "Flexural behavior of self-compacting concrete reinforced with different types of steel fibers,” Constr. Build. Mater., vol. 47, pp. 397-408, 2013.

[8] RILEM TC 162-TDF. Test and design methods for steel fiber reinforced concrete, final recommendations," Mater. Struct. Constr., vol. 36, pp. 579-582, 2002.

[9] BS EN 14651, "Test method for metallic fibred concrete - Measuring the flexural tensile strength (limit of proportionality (LOP), residual),” Br. Stand. Inst., vol. 3, pp. 1-17, 2005.

[10] E. Pereira, "Influência de fibras de aço no comportamento mecânico e nos mecanismos de fissuração de concretos autoadensáveis," MSc dissertation (2017), 170 p. Rio de Janeiro, Brazil: PUCRio.

[11] D.A.S. Rambo, "Concretos autoadensáveis reforçados com fibras de aço híbridas: aspectos materiais e estruturais,” MSc dissertation (2012), 185 p. Rio de Janeiro, Brazil: Universidade Federal do Rio de Janeiro (COPPE/UFRJ).

[12] R. Castoldi, "Propriedades mecânicas e durabilidade de concretos reforçados com fibras de polipropileno e sisal,” MSc dissertation (2018), 147 p. Rio de Janeiro, Brazil: PUC-Rio. 